\title{
A FAMÍLIA ERICACEAE NO BIOMA PAMPA DO RIO GRANDE DO SUL. 1 - AGARISTA CHLORANTHA (CHAM.) G. DON ${ }^{1}$
}

\author{
LEONARDO PAZ DEBLE² JOSÉ NEWTON CARDOSO MARCHIORI ${ }^{3}$ \\ ANABELA SILVEIRA DE OLIVEIRA-DEBLE ${ }^{4}$
}

\section{RESUMO}

Agarista chlorantha (Cham.) G. Don (Ericaceae) é incluída no Bioma Pampa do Rio Grande do Sul com o presente registro de sua ocorrência no topo do Cerro dos Munhoz, município de Santana do Livramento. Palavras-chave: Agarista chlorantha, Ericaceae, Flora do Rio Grande do Sul.

\section{ABSTRACT}

[The family Ericaceae in the Pampa Biome of Rio Grande do Sul State, Brazil. 1 - Agarista chlorantha (Cham.) G. Don].

Agarista chlorantha (Cham.) G. Don (Ericaceae) is included in the Pampas Biome of Rio Grande do Sul State (Brazil) after collections made on the top of "Cerro dos Munhoz", in the munipality of Santana do Livramento.

Key words: Agarista chlorantha, Ericaceae, Flora of Rio Grande do Sul.

\section{INTRODUÇÃO}

Vinculada à "antiga flora das montanhas", a família Ericaceae apresenta no Rio Grande do Sul cerca de 10 espécies na região dos Aparados da Serra e apenas Agarista eucalyptoides G. Don na metade sul do Estado, espécie cuja distribuição geográfica se estende "até a fronteira do Uruguai” (Rambo, 1949). Embora correta, em seus traços gerais, esta abordagem merece reparo no tocante à representação da família no Bioma Pampa, posto que coletas recentes alteram significativamente o quadro exposto. É o caso de Agarista chlorantha (Cham.) G. Don, que passa a integrar a flora deste bioma no Rio Grande do Sul, com base em coletas realizadas no topo do Cerro dos Munhoz, município de Santana do Livramento.

Recebido em 10-11-2012 e aceito para publicação em 05-12-2012.

2 Dr. Professor do Curso de Ciências da Natureza, UNIPAMPA(Dom Pedrito-RS).deble.biol@gmail.com Engenheiro Florestal, Dr. Professor Titular do Departamento de Ciências Florestais, Universidade Federal de Santa Maria. Bolsista de Produtividade em Pesquisa (CNPq - Brasil).

${ }^{4}$ Dra. Professora do Curso de Tecnólogo em Gestão Ambiental, URCAMP (Dom Pedrito - RS).
Sobre este ponto, cabe destacar que a espécie foi anteriormente registrada por Grela \& Brussa (2005) em "cerros chatos" do Departamento de Rivera (Uruguai), suscitando uma investigação detalhada na região fronteiriça do Rio Grande do Sul.

Na literatura botânica brasileira, Agarista chlorantha era reportada apenas para o sudeste do Brasil, desde o Distrito Federal, sul de Minas Gerais e São Paulo, até os estados do Paraná e Santa Catarina (Judd, 1995). Para o último destes estados, Marques (1975) cita coletas procedentes dos municípios de Água Doce, Caçador, Ireneópolis e Praia Grande, todas elas na região fitogeográfica dos Pinhais ou Planalto, de acordo com Reitz et al. (1978). Nesta mesma publicação, Roberto M. Klein informa, em suas "considerações ecológicas", que o limite austral da espécie se encontra na "Zona da matinha nebular que vai desde o Campo dos Padres", no município de Bom Retiro, até a "localidade de Itaimbezinho", no "antigo município de São Francisco de Paula”, Rio Grande do Sul. Roland \& Mondin (2009), mais recentemente, referem cinco coletas de Agarista chlorantha em herbários do Estado. É, justamente, pela notável disjunção verificada entre os 
registros de Grela \& Brussa (2005), em território uruguaio, e a distribuição geográfica referida para a espécie na literatura brasileira, que se justifica a realização da presente pesquisa.

O trabalho de campo foi desenvolvido no município de Santana do Livramento, Rio Grande do Sul, em quatro cerros chatos vinculados à região geomorfológica da Depressão Periférica, situados a leste da cidade: Cerro Trindade ( $\left.30^{\circ} 59^{\prime} 11.81^{\prime \prime} \mathrm{S}, 55^{\circ} 25^{\prime} 24.48^{\prime \prime} \mathrm{O}\right)$, Cerro do Chapéu ( $\left.30^{\circ} 57^{\prime} 9.74^{\prime \prime} \mathrm{S}, 55^{\circ} 28^{\prime} 20.79^{\prime \prime} \mathrm{O}\right)$, Cerro dos Munhoz ( $30^{\circ} 56^{\prime} 11.06^{\prime \prime} \mathrm{S}, 55^{\circ} 23^{\prime} 38.53^{\prime \prime} 0$ ) e Cerro Florentina $\left(30^{\circ} 54^{\prime} 18.61^{\prime \prime} \mathrm{S}, 55^{\circ} 24^{\prime}\right.$ 26.16" O).

Embora variáveis, no tocante a dimensões, estes quatro cerros assemelham-se pela composição geológica, apresentando escarpas verticais areníticas e topo aplanado com rochas muito silicificadas, resistentes ao processo erosivo.

Em todos os quatro cerros foram encontrados indivíduos de Agarista eucalyptoides G. Don no alto das cornijas; Agarista chlorantha, no entanto, foi observada apenas no Cerro dos Munhoz.

Além destas duas Ericáceas, no mesmo ambiente também se encontram indivíduos esparsos de Ilex dumosa Reissek, Ocotea pulchella (Nees) Mez e Ocotea puberula (Rich.) Nees, bem como algumas mirtáceas anãs.

Dos quatro cerros investigados, o Cerro dos Munhoz é o de vegetação melhor preservada, sobretudo pela dificuldade de acesso, inclusive para o gado. Os indivíduos de Agaristha chlorantha se encontram muito espaçadamente ao longo de toda a borda da cornija mas chegam a ser abundantes em alguns pontos, não faltando, inclusive, no interior do platô, em meio a rochas e em associação com o capim-limão (Elionurus sp.). Como importante novidade para a flora do Rio Grande do Sul, é apresentada, na seqüência, uma descrição botânica e ilustrações desta Ericácea pouco conhecida no Estado.

\section{DESCRIÇÃO BOTÂNICA} Agarista chlorantha (Cham.) G. Don, Gen. Hist. 3, p.38. 1934.

Bas.: Andromeda chlorantha Cham., Linnaea 8: 508. 1833. Leucothoe chlorantha (Cham.) DC., Prodr. 7: 604. 1839.

= Andromeda serrulata Cham., Linnaea 8: 506. 1833. Agarista serrulata (Cham.) G. Don, Gen. Hist. 3: 838. 1834. Leucothoe serrulata (Cham.) DC., Prodr. 7: 604. 1839.

= Amechania subcanescens DC. Prodr. 7: 579. 1839. Leucothoe subcanescens (DC.) Meissn., Fl. Brasil. (Martius) 7: 163. t. 62, fig. 1. 1863. Leucothoe chlorantha (Cham.) DC. var. subcanescens (DC.) Sleumer, Bot. Jahrb. Syst. 78: 454. 1959.

Arbustos de 1-2 m, ramificados desde a base, com ramos ascendentes ou patentes, os mais novos pubescentes. Folhas alterno-espiraladas, brevemente pecioladas, com lâminas suavemente discolores, aproximadamente orbiculares, ovadas, oblongas ou elípticas, $1-3 \times 0.5-2 \mathrm{~cm}$, de margens serreadas e revolutas, levemente agudas até rotundas no ápice, rotundas a cordadas na base. Folhas apicais frequentemente avermelhadas e densamente pubescentes, pubescência constituída de tricomas simples e glandulosos entremeados, folhas mais velhas glabrescentes. Inflorescência em racemos terminais ou axilares de 3-12 flores, concentrados na parte distal dos ramos. Raque da inflorescência densamente pubescente, provida de brácteas triangulares. Flores perfeitas, de 8 $14 \mathrm{~mm}$. Sépalas 5, livres, triangulares, 10-15× $1.5-2 \mathrm{~mm}$, pubescentes, com tricomas glandulares e não glandulares. Corola urceolada, provida de cinco pétalas concrescidas, $8-14 \mathrm{~mm} \times$ 4-5 mm, branco-creme ou branco-esverdeada em quase toda a extensão, amarelada ou avermelhada em sua parte distal. Estames 10, livres, com filamentos em forma de fita, com 

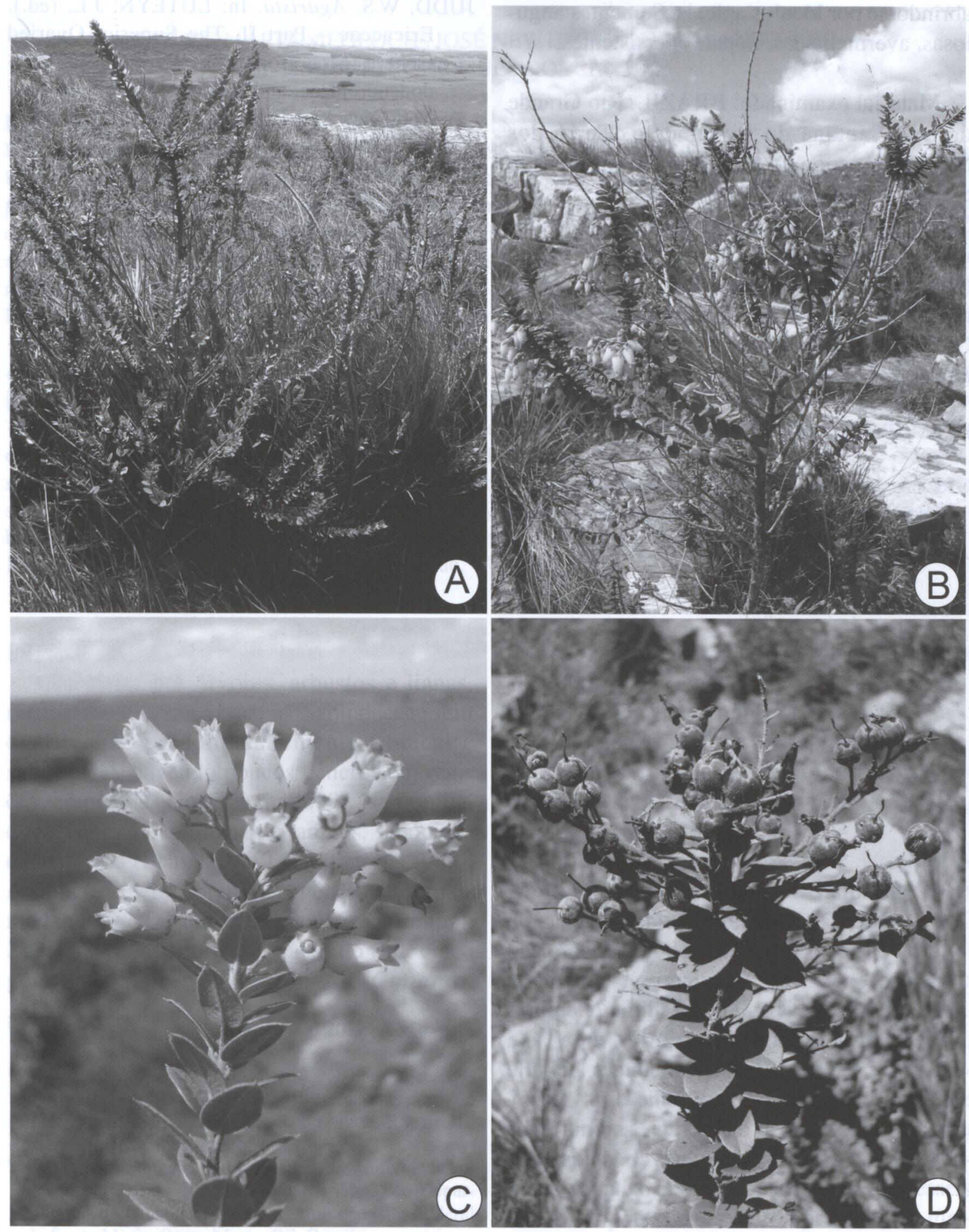

FIGURA 1 - Agarista chlorantha. A, B - Hábito. C - Inflorescência. D - Infrutescência. 
tricomas simples concentrados na metade basal. Fruto do tipo cápsula, esférico, 4-5 × 5-7 mm, abrindo-se por lóculos apicais. Sementes angulosas, avermelhadas. Sépalas persistentes.

Material examinado: BRAZIL. Rio Grande do Sul, Santana do Livramento, Cerro dos Munhoz, no topo do cerro, em campo rupestre e entre rochas, fl., $30^{\circ} 56^{\prime} 16.43^{\prime \prime} \mathrm{S}, 55^{\circ} 23^{\prime}$ 37.21" O, 11-X-2012, L. P. Deble, A. S. de Oliveira-Deble \& J. N. C. Marchiori 14393 (PACA,SI); idem, no topo do cerro, em campo rupestre, fl., fr., $30^{\circ} 56^{\prime} 14.89^{\prime \prime} \mathrm{S}, 55^{\circ} 23^{\prime} 37.12^{\prime \prime}$ O, 9-XI-2012, L. P. Deble, A. S. de OliveiraDeble \& J. N. C. Marchiori 14437 (PACA, SI).

\section{REFERÊNCIAS BIBLIOGRÁFICAS}

GRELA, I.A.; BRUSSA, C.A. Novedades para la flora del Uruguay: nuevo registro de Agarista
(Ericaceae). Acta Bot. Bras., v. 19, n. 3, p. 511514, 2005.

JUDD, W.S. Agarista. In: LUTEYN, J.L. (ed.). Ericaceae - Part II. The Superior-Ovaried Genera (Monotropoideae, Pyroloideae, Rhododendroideae, and Vaccinioideae p. p.). New York: New York Botanical Garden, 1984. p. 295344. (Flora Neotropica; monograph 66).

MARQUES, M. do C. M. Ericáceas. In: REITZ, P.R. Flora Ilustrada Catarinense. Itajaí: Herbário Barbosa Rodrigues, 1975. p. 30-32.

RAMBO, B. A flora de Cambará. Itajaí: Anais Botânicos do Herbário "Barbosa Rodrigues", 1949. p. 117.

REITZ, R.; KLEIN, R.M.; REIS, A. Projeto Madeira de Santa Catarina. Sellowia, Itajaí, n. 28-30, p. 20, 1978.

ROLAND, R. L.; MONDIN, C. A. Sinopse preliminar da Família Ericaceae Juss. no Rio Grande do Sul. In: X Salão de Iniciação Científica PUCRS, Porto Alegre, p. 208-210, 2009. 